\title{
Surface Analysis by MeV Ion Beams and Microscopy
}

José A. R. Pacheco de Carvalho ${ }^{* * *}$, Cláudia F. F. P. R. Pacheco ${ }^{*}$, and António D. Reis ${ }^{*}$

* Remote Detection Unit, ${ }^{* *}$ Informatics Center, University of Beira Interior, Rua Marquês

d'Ávila e Bolama, 6201-001 Covilhã, Portugal

pacheco@ubi.pt

Material analysis, specially surface analysis of materials, has been increasingly important. A wide range of surface analysis techniques is available. The techniques are, generally, complementary. There are nuclear and non-nuclear techniques, e.g. microscopy. Nuclear techniques, which are nondestructive, permit analysis for a few microns near the surface. They have been applied to areas such as scientific, technologic, industry, arts and medicine, using $\mathrm{MeV}$ ion beams [1-6]. Nuclear reactions permit to achieve high sensitivities for detection of light elements in heavy substrates and also discrimination of isotopes. We use ion-ion nuclear reactions, elastic scattering and the energy analysis method, where an energy spectrum is obtained of ions from the target for a chosen energy of the incident ion beam. The target composition and concentration profile information contained in the spectrum is computationally obtained through a computer program that has been developed for predicting such energy spectra [4-5]. Predicted spectra obtained for variations of target parameters are compared with experimental data, giving that information [4-6]. SEM and TEM are also used.

Computer predictions were made, mainly for the ${ }^{12} \mathrm{C}\left(\mathrm{d}, \mathrm{p}_{0}\right){ }^{13} \mathrm{C}$ reaction and uniform, flat ${ }^{12} \mathrm{C}$ target. Available data were used for differential cross sections and stopping powers. Measurements for that reaction at $165^{\circ}$ and $135^{\circ}$ (Fig. 1.-A) were included [4]. Options in the base computations [5] were considered, such as incident beam size and angular divergence, detector angular aperture, LindhardScharff energy straggling theory and Fermi theory for multiple scattering. $\mathrm{X}_{\mathrm{i}}$ is a target or target layer thickness parameter. Prediction stages of target yields were calculated for several target thicknesses, both for thin films (Fig. 1.-B) and thick targets. In the former case, a narrow peak arises. In the latter case, final yield resembles the differential cross section curve.

A thick, high purity sample of pyrolitic graphite, whose flatness was checked by SEM, was used in the $(d, p)$ experiments in ${ }^{12} \mathrm{C}$. Another sample was a thick flat quartz target, $\mathrm{SiO}_{2}$, having a thin surface film of carbon, used for $(\mathrm{d}, \mathrm{p})$ in ${ }^{12} \mathrm{C}$ and $(\mathrm{d}, \mathrm{p}),(\mathrm{d}, \alpha)$ in ${ }^{16} \mathrm{O}$. A further sample, designated as $\mathrm{Al} / \mathrm{Al}_{2} \mathrm{O}_{3}$, was obtained by aluminium anodization at $100 \mathrm{~V}$ in an aqueous solution of tri-ammonium citrate. TEM microscopy has shown substrate flatness and good oxide uniformity (Fig. 1-E) with a thickness of $0.1340 \mu \mathrm{m}$, close to the expected nominal value of $0.1370 \mu \mathrm{m}$. Computer fits to experimental spectra of the ${ }^{12} \mathrm{C}\left(\mathrm{d}, \mathrm{p}_{0}\right){ }^{13} \mathrm{C}$ reaction at $\mathrm{E}_{\mathrm{d}}=1.40$ and $1.0 \mathrm{MeV}$, gave ${ }^{12} \mathrm{C}$ uniform concentrations and thicknesses $X_{1}=10 \mu \mathrm{m}$ (Fig. 1-C) and $X_{1}=0.062 \mu \mathrm{m}$ (Fig. 1-D) for the $C$ thick target and thin film, respectively. Similarly, through elastic scattering of $\alpha$ particles at $\mathrm{E}_{\alpha}=2.0 \mathrm{MeV}$, we obtained an oxide film thickness of $0.1350 \mu \mathrm{m}$, very close to the TEM value. The fit (Fig. 1-F) indicates that the ratio of atomic densities of $\mathrm{O}$ and $\mathrm{Al}$ is slightly higher than 1.5. The combined use of nuclear techniques, SEM and TEM microscopy has proved to be very important for surface analysis of materials. Most of the reported results would be difficult to obtain by other techniques.

\section{References}

[1] J. R. Tesmer, M. Nastasi (Eds.), Handbook of Modern Ion Beam Materials Analysis, Materials Research Society, Pittsburgh, PA, 1995. 
[2] G. Amsel, G. Battistig, Nucl. Instr. and Meth. B 240 (2005) 1.

[3] J. M. Calvert, D. J. Derry, D. G. Lees, J. Phys. D: Appl. Phys. 7 (1974) 940.

[4] J. A. R. Pacheco de Carvalho, A. D. Reis, Nucl. Instr. and Meth. B 266, 10 (2008) 2263.

[5] J. A. R. Pacheco de Carvalho, A. D. Reis, Bol. Soc. Esp. Ceram. V. 47, 4 (2008) 252.

[6] J. A. R. Pacheco de Carvalho, A. D. Reis, Microsc. Microanal. 14, S3 (2008) 71.

Project funded by FCT (Fundação para a Ciência e a Tecnologia) / POCI2010.

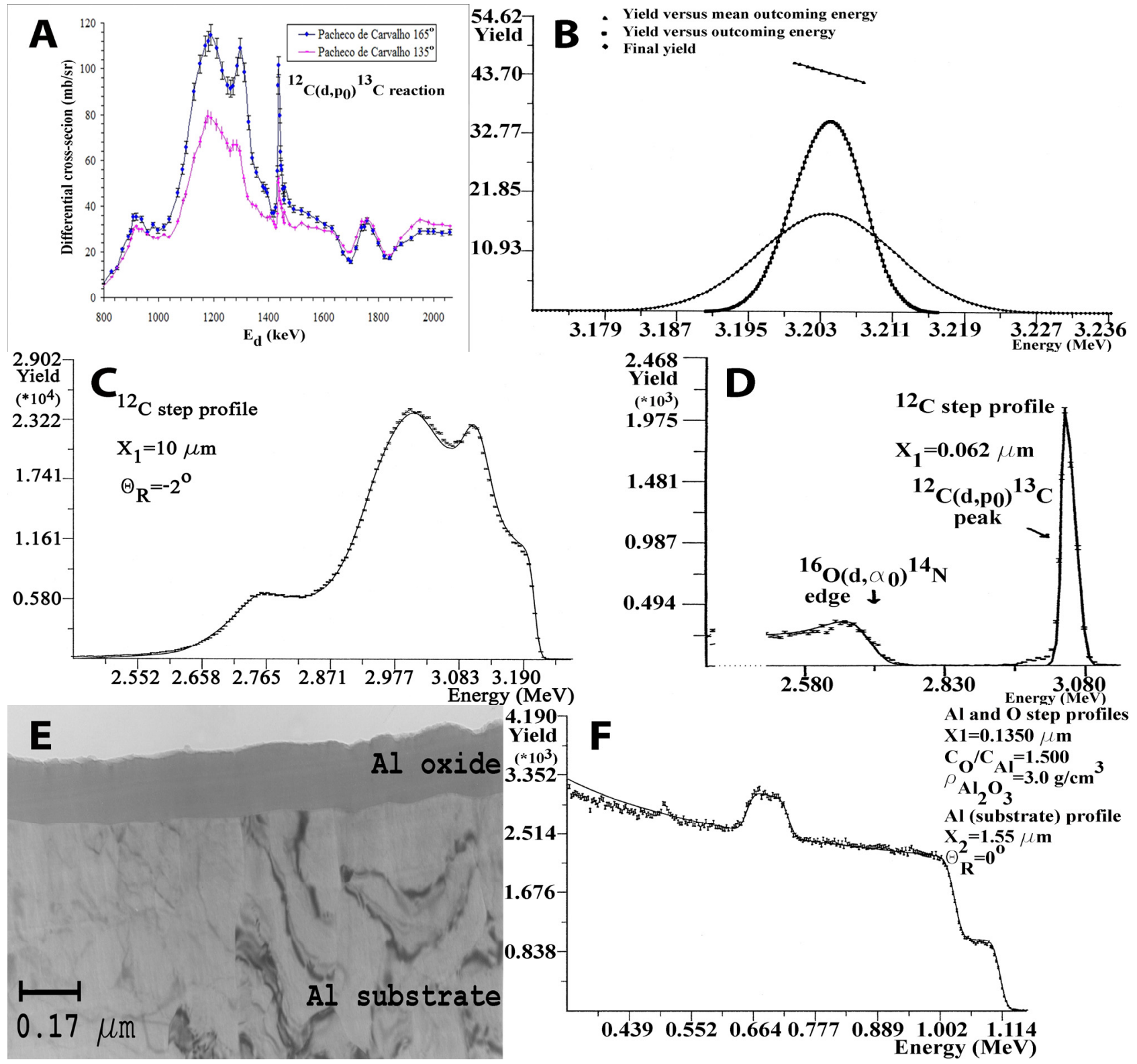

Fig. 1. Differential cross section, computed fits to energy spectra and TEM micrograph.

A. Differential cross section measurements for the ${ }^{12} \mathrm{C}\left(\mathrm{d}, \mathrm{p}_{0}\right){ }^{13} \mathrm{C}$ reaction at laboratory angles of $165^{\circ}$ and $135^{\circ}$ [4]. B. Prediction stages for the ${ }^{12} \mathrm{C}\left(\mathrm{d}, \mathrm{p}_{0}\right){ }^{13} \mathrm{C}$ reaction and a ${ }^{12} \mathrm{C}$ target thickness $\mathrm{X}_{1}=0.125$ $\mu \mathrm{m}$ at $\mathrm{E}_{\mathrm{d}}=1.40 \mathrm{MeV}$ and $165^{\circ} . \mathrm{C} .{ }^{12} \mathrm{C}\left(\mathrm{d}, \mathrm{p}_{0}\right){ }^{13} \mathrm{C}$ reaction in the $\mathrm{C}$ target, $\mathrm{E}_{\mathrm{d}}=1.40 \mathrm{MeV}, 165^{\circ}$. D. $(\mathrm{d}, \mathrm{p})$ and $(\mathrm{d}, \alpha)$ reactions in the quartz target, $\mathrm{E}_{\mathrm{d}}=1.0 \mathrm{MeV}, 135^{\circ}$. E. TEM micrograph of the $\mathrm{Al} / \mathrm{Al}_{2} \mathrm{O}_{3}$ target. F. Elastic scattering in the $\mathrm{Al} / \mathrm{Al}_{2} \mathrm{O}_{3}$ target, $\mathrm{E}_{\alpha}=2.0 \mathrm{MeV}, 165^{\circ}$. 